\title{
Decreases in Casz1 mRNA by an siRNA Complex Do not Alter Blood Pressure in Mice
}

\author{
Su-Min Ji, Young-Bin Shin, So-Yon Park, Hyeon- \\ Ju Lee and Bermseok Oh*
}

Department of Biomedical Engineering, Kyung Hee University School of Medicine, Seoul 130-702, Korea

\begin{abstract}
Recent genomewide association studies of large samples have identified genes that are associated with blood pressure. The Global Blood Pressure Genetics (Global BPgen) and Cohorts for Heart and Aging Research in Genome Epidemiology (CHARGE) consortiums identified 14 loci that govern blood pressure on a genomewide significance level, one of which is CASZ1 confirmed in both Europeans and Asians. CASZ1 is a zinc finger transcription factor that controls apoptosis and cell fate and suppresses neuroblastoma tumor growth by reprogramming gene expression, like a tumor suppressor. To validate the function of $C A S Z 1$ in blood pressure, we decreased Casz1 mRNA levels in mice by siRNA. Casz1 siRNA reduced mRNA levels by $59 \%$ in a mouse cell line. A polyethylenimine-mixed siRNA complex was injected into mouse tail veins, reducing Casz1 mRNA expression to $45 \%$ in the kidney. However, blood pressure in the treated mice was unaffected, despite a 55\% reduction in Casz1 mRNA levels in the kidney on multiple siRNA injections daily. Even though Casz1 siRNA-treated mice did not experience any significant change in blood pressure, our study demonstrates the value of in vivo siRNA injection in analyzing the function of candidate genes identified by genomewide association studies.
\end{abstract}

Keywords: association analysis, blood pressure, CASZ1, expression

\section{Introduction}

CASZ1 gene is a zinc finger transcription factor that controls cell fate, although little is known about its function [1]. CASZ1 is also known as a survival-related gene that has 2 isoforms. It encodes a putative protein of 172

*Corresponding author: E-mail: ohbs@khu.ac.kr

Tel +82-2-961-0617, Fax +82-2-961-5515

Received 21 December 2011, Revised 1 February 2012, Accepted 8 February 2012 amino acids that localizes predominantly in the perinuclear region, as predicted for transcription factors. CASZ1 is highly expressed in many human cancer cell lines, although its expression is low in most tissues, implicating it in tumor growth [2].

These findings indicate that $C A S Z 1$ is important for cell proliferation, development, and differentiation, as well as carcinogenesis. However, CASZ1 has recently been reported to be significantly associated with blood pressure and hypertension in genomewide association studies (GWASs) [3]. Blood pressure GWASs by the Global Blood Pressure Genetics (Global BPgen) [4] and the Cohorts for Heart and Aging Research in Genome Epidemiology (CHARGE) consortium [5] have identified 14 independent loci that govern blood pressure or hypertension at a genomewide significance level, 7 of which were replicated in the Japanese population (CASZ1, MTHFR, ITGA9, FGF5, CYP17A1-CNNM2, ATP2B1, and CSK-ULK3) [6].

Single nucleotide polymorphism (SNP) rs880315, which lies in an intron of CASZ1, was one of the 7 replicate loci $\left(p=2.2 \times 10^{-8}, p=4.9 \times 10^{-12}\right.$, and $p=3.0$ $\times 10^{-7}$ for systolic blood pressure, diastolic blood pressure, and hypertension, respectively). CASZ1 was also linked to blood pressure in the Women's Genome Health Study (rs880315; $p=5.2 \times 10^{-9}$ for systolic blood pressure) [7]. Recently, the CASZ1 locus was identified in 19,608 subjects of east Asian ancestry by the Asian Genetic Epidemiology Network Blood Pressure (AGEN-BP) consortium [8].

Although these blood pressure GWASs have suggested that these loci control blood pressure, their function in blood pressure has not been examined. Traditionally, knockout or transgenic mice have been used to reveal gene function and can be good approaches for examining candidate genes that lie near the GWAS loci [9]. However, this process is expensive and time-consuming [10], requiring technical advances to determine their function in vivo.

Small interfering RNA (siRNA) is an alternative approach that has the potential to become the preferred tool for that purpose [11]. In vivo injection of siRNA reduces gene expression by $70 \%$ to $80 \%$ in certain tissues in mice, demonstrating its efficacy [12].

However, specific tissues can not be targeted by in vivo injection of siRNA, and the injected siRNA is unstable in blood serum, limiting their use in delivering siRNA in vivo. It also has certain disadvantages, such 
as effecting inflammatory responses and toxicity [13]. Thus, developing siRNA delivery methods in animal models is a challenging but worthy effort to accelerate the discovery of novel genes [11].

We sought to determine whether murine Casz1 controls blood pressure by administering Casz1 siRNA to mice. A polyethylenimine-mixed siRNA complex was injected into tail veins, and changes in Casz1 mRNA and blood pressure were measured.

\section{Methods}

\section{Animals}

BALB/c mice (Japan SLC, Inc., Shizuoka, Japan) were bred in a pathogen-free facility and used at 7 to 9 weeks of age for siRNA injection. The mice were maintained on a 12-h light/dark cycle at a constant temperature with free access to food and water. Every effort was made to minimize the number of animals that was used and their suffering per the Committee for the Care and Use of Laboratory Animals, College of Pharmacy, Kyung Hee University (KHP-2010-04-06).

\section{Synthesis of siRNA}

Casz1 siRNA oligonucleotides were synthesized by Genolution (Seoul, Korea). The target sequence for Casz1 was 5'-GATGTGATCCGACATTACA-3' (siRNA\#1), 5'CTAGAACTGCTCTGTATGT-3' (siRNA\#2), and 5'-CAATTCGGCAAGTAATGGA-3' (siRNA \#3), and nonspecific scrambled siRNA was used as a negative control.

To examine the efficacy of siRNAs, siRNAs were transfected into B16F10 cells using G-Fectin (Genolution); 1-2 $\mu \mathrm{L}$ of $\mathrm{G}$-Fectin and $20 \mathrm{nM}$ siRNA were added to 50 $\mu \mathrm{L}$ phosphate buffered saline, and the reaction was incubated for $10 \mathrm{~min}$ at room temperature (RT). B16F10 cells were used to seed 24-well plates at $5 \times 10^{4}$ cells/well and $30 \%$ confluence, and the transfection mixture was added to the plate. The cells were harvested for RNA extraction after $24 \mathrm{~h}$ of incubation. Total RNA was prepared using TRIzol (Invitrogen, Carlsbad, CA, USA) per the manufacturer's instructions.

\section{Delivery methods}

The transfection agent was in vivo-jetPEI ${ }^{\mathrm{TM}}$ (Polyplus, Illkirch-Graffenstaden, France). Per the manufacturer, 25 $\mu \mathrm{g}$ siRNA and $6.5 \mu \mathrm{L}$ vivo-jetPEI ${ }^{\mathrm{TM}}$ (N/P charge ratio of 6) were diluted with $50 \mu \mathrm{L} 10 \%$ glucose solution and 50 $\mu \mathrm{L}$ sterile $\mathrm{H}_{2} \mathrm{O}$. The solution was vortexed gently and left for $15 \mathrm{~min}$ at RT. The mixture was injected into the tail veins of 7 - to 9-week-old mice, and the treated mice were measured for blood pressure or sacrificed for RNA extraction.

\section{RNA extraction and real-time PCR}

RNA was extracted from the tissues of siRNA-treated mice with TRIzol (Invitrogen). We synthesized cDNA from 500 ng of total RNA using the PrimeScript ${ }^{T M}$ RT reagent kit (TaKaRa, Otsu, Japan) per the manufacturer's protocol. Casz1 mRNA was analyzed by real-time PCR. One-tenth of the cDNA reaction was added to a final volume of $20 \mu \mathrm{L}$ for each reaction containing SYBR Green I (TaKaRa). The primers for Casz1 and glyceraldehye-3-phosphate dehydrogenase $(G A P D H)$ were 5'GTCTCTTCGGGAACTGCAAG-3'/5'-TGGGACACAGGCA CTGTAGA-3' and 5'-GCTCTCTGCTCCTCCTGTTC-3'/5'CAATACGACCAAATCCGTTG-3', respectively (forward/reverse sequence).

Quantitative real-time PCR was performed on an $A B I$ Step One Real-time PCR system (Applied Biosystems, Foster, CA, USA) using the following program: 45 cycles of $95^{\circ} \mathrm{C}$ for $10 \mathrm{~s}, 60^{\circ} \mathrm{C}$ for $15 \mathrm{~s}$, and $72^{\circ} \mathrm{C}$ for $20 \mathrm{~s}$. To normalize the amount of sample cDNA in each reaction, the Ct value of each target gene was subtracted by that of $G A P D H$ to obtain delta Ct [14]. To calculate the fold-change in expression, the delta $\mathrm{Ct}$ value of the case sample was subtracted by that of the control (delta delta $\mathrm{Ct}=$ delta $\mathrm{Ct}$ case - delta $\mathrm{Ct}$ control).

Reverse-transcription PCR was performed similarly to quantitative real-time PCR, except that it used 35 cycles for amplification. The PCR products were separated by electrophoresis in a $2.0 \%$ agarose gel and visualized under UV lamp after ethidium bromide staining.

\section{Blood pressure measurement}

Blood pressure was recorded intraarterially with a computerized data acquisition system (ADInstruments, Bella Vista, Australia). To place the intraarterial catheter, mice were anesthetized with avertin. The standard dose was $0.014 \mathrm{~mL} / \mathrm{g}$ avertin, which was made by diluting stock

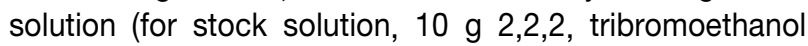
dissolved in $10 \mathrm{~mL}$ tertiary amyl alcohol) 40 -fold in $0.9 \%$ $\mathrm{NaCl}$. The intraarterial catheter, a polyethylene tube $(0.2$ $\mathrm{mm}$ I.D., $0.5 \mathrm{~mm}$ O.D.) (Natsume, Tokyo, Japan) that was filled with $0.9 \% \mathrm{NaCl}$ containing $100 \mathrm{U} / \mathrm{mL}$ heparin, was inserted into the right carotid artery and tied in place.

The blood pressure in the vessel was transmitted along the catheter to the transducer's diaphragm (MLT0699 Disposable BP Transducer; ADInstruments). The diaphragm signal was amplified through a Bridge Amplifier and recorded on a PowerLab system (LabChart 7.2; ADInstruments). Blood pressure was 
monitored for $2 \mathrm{~h}$ after the injection of the anesthetic and calculated as the average blood pressure between $45 \mathrm{~min}$ and $75 \mathrm{~min}$ after the injection (1 point per min). Statistical analysis was performed using PASW Statistics version 18.0 (SPSS Inc., Chicago, IL, USA), and differences in blood pressure between case and control groups were analyzed by independent sample t-test.

\section{Results}

Reduction in Casz1 mRNA by siRNA injection into tail vein

We examined the efficacies of 3 Casz1 siRNA oligonu-

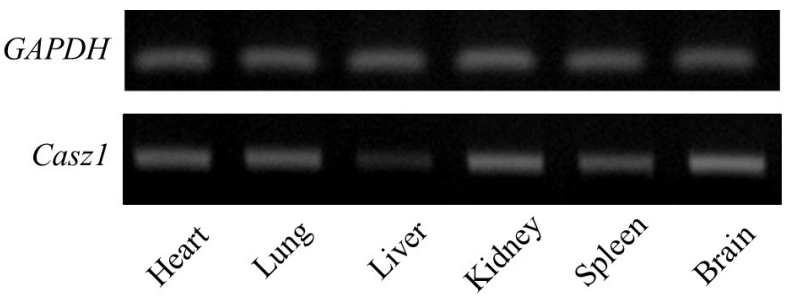

Fig. 1. Casz1 mRNA expression in normal mouse tissues. $G A P D H$, glyceraldehye-3-phosphate dehydrogenase.

(A)

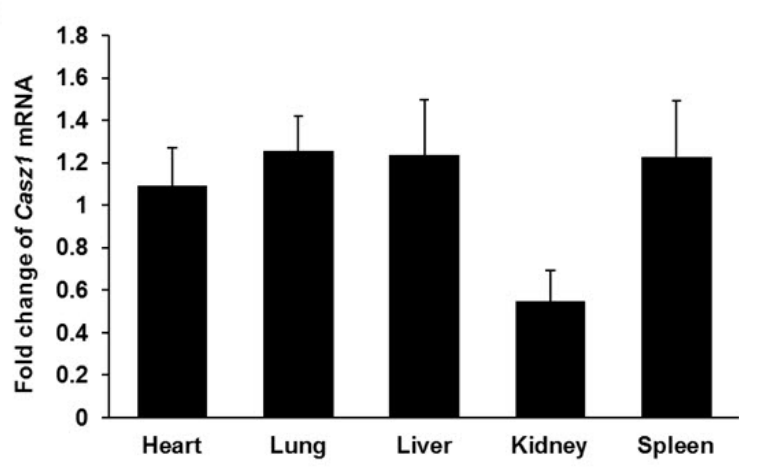

(B)

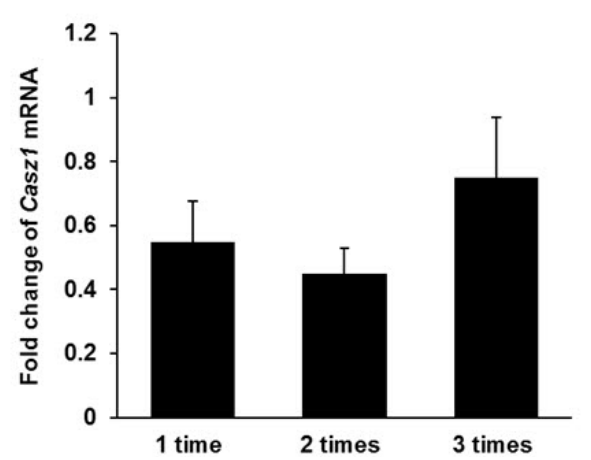

Fig. 2. Decreases in Casz1 mRNA by an siRNA complex. (A) Fold-change in Casz1 mRNA levels in tissues in siRNAinjected mice ( $\mathrm{n}=2$ per tissue). (B) Reduction in Casz1 mRNA levels in kidney by in vivo siRNA injection. cleotides in the B16F10 mouse melanoma cell line. By real-time PCR, Casz1 mRNA levels fell 0\%, 59\%, and $54 \%$, and we selected the second siRNA for the in vivo experiments.

Prior to the injection of siRNA, Casz1 expression in heart, lung, liver, kidney, spleen, and brain was measured by reverse-transcription PCR. Casz1 was expressed in most tissues and at relatively low levels in liver (Fig. 1).

Casz1 siRNA was mixed with polyethylenimine, and the complex was injected into the tail veins of mice. At $24 \mathrm{~h}$ after siRNA injection, various tissues of siRNAtreated mice were analyzed with regard to Casz1 mRNA levels. Casz1 mRNA expression was normalized to $G A P D H$, and a scrambled siRNA was used as control.

By quantitative real-time PCR, Casz1 mRNA levels declined only in kidney (Fig. 2A). Casz1 mRNA levels in the kidney fell by $45 \%, 55 \%$, and $25 \%$ after 1,2 , and 3 injections per day, respectively ( $n=3$ for each group) (Fig. 2B).

\section{Blood pressure in siRNA-injected mice}

Blood pressure was measured $24 \mathrm{~h}$ after tail vein injection of the scrambled or Casz1 siRNA (control, $\mathrm{n}=$ 4; case, $n=3$ ). Using an intraarterial catheter that was connected to a pressure sensor, we recorded blood pressure continuously for $2 \mathrm{~h}$ after anesthesia. Blood pressure did not change after a 1-time injection $(\mathrm{p}=$ 0.713 ). Thus, we injected siRNA twice each day (control, $\mathrm{n}=4$; case, $\mathrm{n}=6$ ) but did not observe any significant difference between the case and control groups ( $p=$ $0.545)$. After 3 siRNA injections daily for 3 days, blood pressure was also unaffected $(p=0.297$ ) (Table 1 , Supplementary Table 1).

\section{Discussion}

This study attempted to validate $C A S Z 1$ as a regulator of blood pressure using siRNA in mice. Although Casz1 mRNA levels decreased by $55 \%$ in kidney, blood pressure did not change on injection of the siRNA complex into tail veins.

It is difficult to conclude that $C A S Z 1$ does not control

Table 1. Blood pressure in siRNA-injected mice

\begin{tabular}{lcccccc}
\hline & \multicolumn{2}{c}{ No. of mice } & \multicolumn{4}{c}{ Blood pressure $(\mathrm{mm} \mathrm{Hg})$} \\
\cline { 2 - 6 } & Control & Casz1 & Control & Casz1 & \\
\hline 1-time & 4 & 3 & $83.93 \pm 3.27$ & $85.48 \pm 7.19$ & 0.713 \\
2-times & 4 & 6 & $76.75 \pm 0.91$ & $80.34 \pm 6.26$ & 0.545 \\
3-times & 4 & 4 & $89.83 \pm 4.81$ & $88.24 \pm 1.17$ & 0.297 \\
\hline
\end{tabular}


blood pressure, because this study has several limitations. First, Casz1 mRNA levels in kidney were reduced up to 55\%; if Casz1 expression had been abolished, we might have detected a significant difference in blood pressure between the case and control groups. Second, it is possible that CASZ1 functions in other tissues besides the kidney in the regulation of blood pressure. The kidney is an essential organ of the urinary system and controls homeostatic functions, such as the regulation of blood pressure, by maintaining salt and water balances. However, the function of $C A S Z 1$ in kidney is unknown due to the lack of Casz1 functional studies in kidney. Casz1 is highly expressed in brain, but siRNA nanoparticles do not access the brain due to the blood-brain barrier [15]. Third, human CASZ1 is $87 \%$ and $90 \%$ identical to mouse Casz 1 in the cDNA and polypeptide sequences, respectively [1]. Nevertheless, it is possible that Casz1 function differs between the two species.

Because most loci that have been identified by GWASs have several genes nearby, it may be necessary to examine many candidates to identify the functional gene. Knockout and transgenic mice are expensive and time-consuming to generate. In contrast, siRNA injection costs less and is much faster to perform, making siRNA injection suitable for functional validation studies of GWAS results.

In summary, we did not observe any significant change in blood pressure in Casz1 siRNA-treated mice, but our study demonstrates the value of in vivo siRNA injection in the functional analysis of candidate genes from GWASs.

\section{Supplementary materials}

Supplementary data including a table can be found with this article online at http://www.genominfo.org/html/ UploadFile/article6_201203_SP.pdf.

\section{Acknowledgments}

This work was supported by the Basic Science Research Program through a National Research Foundation of Korea (NRF) grant, funded by the Korean government (MEST) (2011-0017952).

\section{References}

1. Liu Z, Yang X, Tan F, Cullion K, Thiele CJ. Molecular cloning and characterization of human Castor, a novel human gene upregulated during cell differentiation. Biochem Biophys Res Commun 2006;344:834-844.
2. Yuan ZR, Wang R, Solomon J, Luo X, Sun H, Zhang L, et al. Identification and characterization of survival-related gene, a novel cell survival gene controlling apoptosis and tumorigenesis. Cancer Res 2005;65:1071610724.

3. Levy D, Ehret GB, Rice K, Verwoert GC, Launer LJ, Dehghan A, et al. Genome-wide association study of blood pressure and hypertension. Nat Genet 2009;41: 677-687.

4. Newton-Cheh C, Johnson T, Gateva V, Tobin MD, Bochud M, Coin L, et al. Genome-wide association study identifies eight loci associated with blood pressure. Nat Genet 2009;41:666-676.

5. Psaty BM, O'Donnell CJ, Gudnason V, Lunetta KL, Folsom AR, Rotter JI, et al. Cohorts for Heart and Aging Research in Genomic Epidemiology (CHARGE) Consortium: design of prospective meta-analyses of genome-wide association studies from 5 cohorts. Circ Cardiovasc Genet 2009;2:73-80.

6. Takeuchi $\mathrm{F}$, Isono M, Katsuya T, Yamamoto K, Yokota $\mathrm{M}$, Sugiyama $\mathrm{T}$, et al. Blood pressure and hypertension are associated with 7 loci in the Japanese population. Circulation 2010;121:2302-2309.

7. Ho JE, Levy D, Rose L, Johnson AD, Ridker PM, Chasman DI. Discovery and replication of novel blood pressure genetic loci in the Women's Genome Health Study. J Hypertens 2011;29:62-69.

8. Kato N, Takeuchi F, Tabara Y, Kelly TN, Go MJ, Sim $X$, et al. Meta-analysis of genome-wide association studies identifies common variants associated with blood pressure variation in east Asians. Nat Genet 2011;43: 531-538.

9. Davey RA, MacLean HE. Current and future approaches using genetically modified mice in endocrine research. Am J Physiol Endocrinol Metab 2006;291: E429-E438.

10. Rubinson DA, Dillon CP, Kwiatkowski AV, Sievers C, Yang L, Kopinja J, et al. A lentivirus-based system to functionally silence genes in primary mammalian cells, stem cells and transgenic mice by RNA interference. Nat Genet 2003;33:401-406.

11. Xie FY, Woodle MC, Lu PY. Harnessing in vivo siRNA delivery for drug discovery and therapeutic development. Drug Discov Today 2006;11:67-73.

12. Musunuru K, Strong A, Frank-Kamenetsky M, Lee NE, Ahfeldt T, Sachs KV, et al. From noncoding variant to phenotype via SORT1 at the $1 \mathrm{p} 13$ cholesterol locus. Nature 2010;466:714-719.

13. Shim MS, Kwon YJ. Efficient and targeted delivery of siRNA in vivo. FEBS $J$ 2010;277:4814-4827.

14. Livak KJ, Schmittgen TD. Analysis of relative gene expression data using real-time quantitative PCR and the 2(-Delta Delta C(T)) Method. Methods 2001;25:402-408.

15. Alyaudtin RN, Reichel $A$, Löbenberg $R$, Ramge $P$, Kreuter J, Begley DJ. Interaction of poly(butylcyanoacrylate) nanoparticles with the blood-brain barrier in vivo and in vitro. J Drug Target 2001;9:209-221. 